\title{
A DIMENSÃO EXPERIENCIAL COMO ELEMENTO CONSTITUTIVO DA IDENTIDADE DOCENTE
}

\author{
NATAL LÂNia RoQUe FERnANDES \\ Instituto Federal de Educação, Ciência e Tecnologia do Ceará (IFCE) \\ Mestrado Profissional em Educação Profissional e Tecnológica \\ $<$ natallania@ifce.edu.br>
}

DOI: $10.21439 /$ conexoes.v11i2.1090

\begin{abstract}
Resumo. A partir de um olhar bibliográfico multirreferencial, o texto apresenta uma reflexão sobre a importância da experiência no processo identitário da profissão docente. De acordo com Dubar (2006), o processo identitário constitui-se por processos de individualização e socialização do sujeito. Pode-se dizer que é um processo dual em que acontecem duas transações, conforme identificado por Dubar (2005): uma interna ao indivíduo, e outra, externa, entre o indivíduo e as instituições com as quais ele interage em sua globalidade. Essa interação acontece por meio da experiência. A experiência implica o sujeito em sua globalidade, pois comporta as dimensões sensíveis, afetivas e conscienciais que envolvem emoções, sentimentos, valores e imagens sociais, construídas ao longo de uma vida. A identidade profissional do professor como parte constitutiva do sujeito social é também o resultado do processo dual de individualização e socialização do sujeito. Nesse processo, a experiência ocupa uma dimensão relevante para a identificação ou pertencimento do sujeito à profissão docente, pois a docência é construída ao longo de um percurso, influenciada por diversos espaços de socialização e experiência.
\end{abstract}

Palavras-chaves: Identidade. Docência. Experiência. Individualização. Socialização.

\begin{abstract}
From a multireferencial bibliographic look, the text presents a reflection about the importance of experience in the identity process of the teaching profession. According to Dubar (2006), the identity process is constituted by individualization and socialization processes of the subject. One can say that it is a dual process taking place two transactions, as identified by Dubar (2005): one, within the individual, and another, external, between the individual and the institutions with which it interacts in its entirety. This interaction takes place through experience. Experience implies the subject in its entirety, because it holds the sensitive, affective and consciential dimensions involving emotions, feelings, values and social images, built up over a lifetime. The professional identity of the teacher as a constituent part of the social subject is also the result of the dual process of individualization and socialization of the subject. In this process, the experience takes a relevant dimension for identification or belonging of the subject to the teaching profession because teaching is built along a route, influenced by several spaces of socialization and experience.
\end{abstract}

Keywords: Identity. Teaching. Experience. Individualization. Socialization.

\section{INTRODUÇÃO}

As reflexões presentes no texto tiveram início durante a escrita da tese de doutorad $\oint^{1}$, na qual realizamos

\footnotetext{
${ }^{1}$ Título da tese: Processos identitários docentes: percursos de vida e de trabalho no contexto do PROEJA do Instituto Federal de Educação, Ciência e Tecnologia do Ceará. O artigo é referente ao capítulo I intitulado: Processos identitários da docência: entre a atribuição e o
}

estudos sobre os processos identitários de professores com docência em EJA, tendo como sujeitos professores da educação profissional que lecionavam nos cursos técnicos integrados ao ensino médio na modalidade

pertencimento. 
Educação Jovens e Adultos, vinculados ao PROEJA $2^{2}$ do Instituto Federal de Educação, Ciências e Tecnologia IFCE, Fortaleza. Dentre os estudos teóricos necessários para a compreensão desses processos, tais como: sobre Educação de Jovens e Adultos, Educação profissional, identidade, experiências, (auto)biografia, optamos por apresentar neste texto as discussões elaboradas sobre a relação entre processos identitários e experiência.

Portanto, neste texto apresento aportes teóricos que nos subsidiaram a alcançar o objetivo de refletir sobre a importância da experiência para a constituição da profissão docente, concebendo-a como um processo de reflexividade pelo qual os diferentes processos identitários são construídos e transformados. A partir de um olhar multirreferencial, faremos uma incursão bibliográfica nos estudos sobre identidade e experiência, tomando como aportes diferentes teóricos os quais contribuem para o entendimento dessas categorias, tendo como mirante a profissão docente.

No primeiro momento, dialogamos, dentre outros autores, com Hall (2006) e Dubar (2006), sobre processos identitários, Ricoeur (1997) e Delory-Momberger (2008), para entendermos o conceito de identidade biográfica e com Moita (1995) discutiremos sobre identidade docente. No segundo momento, refletimos o conceito de experiência, a partir de autores como: Dubet (1994), Larrosa (2004) e Thompson (1981). Para introduzir a ideia de experiência formativa, buscamos contribuição nos estudos em Josso et al. (2004) e Dewey (1971). Por fim, no terceiro momento, com o fito de corroborar com a concepção de experiência como elemento formativo e constitutivo da identidade docente, dialogamos com atores como Schön (2000) que concebe o professor como um profissional que reflete na e sobre sua ação, bem como com e Tardif, Lessard e Lahaye (1991), os quais identificam o rol de saberes constitutivos da docência, dentre eles o saber da experiência.

\section{IDENTIDADE: PROCESSOS RELACIONAIS E BIOGRÁFICOS}

O caráter polissêmico do conceito de identidade revelase nas diferentes abordagens cunhadas pelas áreas de conhecimento, todavia, observa-se que as diferentes conceituações pautam-se na relação entre interioridade e exterioridade, ora priorizando uma ou outra ou a interação entre elas. O conceito de identidade tem sido abordado por diferentes perspectivas em consonância

\footnotetext{
${ }^{2}$ Programa Nacional de Integração da Educação Profissional com a Educação Básica na Modalidade de Educação de Jovens e Adultos.
}

com a concepção de sujeito forjada pelos diversos movimentos teóricos e ideológicos surgidos no decorrer da história. De forma geral, as diferentes conceituações podem ser agrupadas por duas grandes linhas de pensamentos: a essencialista e a não essencialista. A essencialista defende a existência de um núcleo cristalino e, portanto, todos os indivíduos têm características iguais e imutáveis. A não essencialista considera as identidades comuns e as diferenças entre elas e argumenta sobre as transformações pelas quais passam as identidades ao longo do tempo.

Hall (2006), teórico representante do campo dos estudos culturais, movimento surgido na Inglaterra no século XX, desenvolvendo estudos com ênfase na identidade cultural, tem contribuído para o entendimento da polissemia de abordagens sobre o tema. No livro intitulado A identidade cultural na pós-modernidade, o autor distingue três concepções diferentes de sujeitos: a Iluminista, a Sociológica e a Pós-moderna.

$\mathrm{Na}$ concepção iluminista, de cunho essencialista, o sujeito é considerado como um indivíduo totalmente imutável, dotado de razão, consciência e ação. A identidade se constitui na existência de um núcleo interior central que nasce com ele e permanece ao longo de sua existência. O sujeito é o ser racional, único, soberano. A razão, que é o centro do indivíduo, independente de influências exteriores, existe por si mesma e exerce controle sob as atividades do mesmo. A visão essencialista construiu a ideia de sujeito como uma imagem de si mesmo, individual, com uma identidade única, biológica e naturalmente fixa do nascimento até a morte. Esta concepção nega a existência de uma identidade social, prevalecendo, assim, apenas a interioridade na constituição da identidade.

Em meio à complexidade da vida moderna, forja-se a concepção sociológica baseada na ideia de entrelaçamento do sujeito com o meio social, ou seja, a identidade é formada e modificada por meio de diálogo com as diversas culturas do mundo em que o sujeito habita. A formação da identidade se dá pela interação entre os aspectos endógenos e exógenos; pela interação entre o sujeito e a razão; entre a subjetividade e a objetividade; entre o individual e coletivo. Nessa concepção, não é negado os aspectos endógenos, ou seja, a consciência individual do sujeito. No entanto, considera-se a influência de fatores exógenos, tais como as formas padronizadas de condutas e pensamentos existentes no interior de qualquer grupo ou sociedade, as quais compõem a identidade coletiva ou social.

Éstas identidades colectivas se refieren a sistemas de acción e interpretación que, siendo 


\section{A DIMENSÃO EXPERIENCIAL COMO ELEMENTO CONSTITUTIVO DA IDENTIDADE DOCENTE}

concebidos por los actores en interacción social, pueden, posteriormente, ser más o menos resistentes a, o elicitadores de, las tentativas individuales, o incluso grupales, de cambio (LOPES, 2011, p. 4).

A identidade social corresponde à ação social, aos papéis que cada indivíduo assume na sociedade. No entanto, os papéis sociais e a cultura não são suficientes para definir os elementos estáveis da ação, porque os indivíduos não cumprem um programa, mas constroem uma unidade a partir dos elementos de sua vida social e da multiplicidade das orientações que eles utilizam. Assim, a identidade social não é um ser, mas uma prática (DUBET, 1994).

A terceira concepção identificada por Hall (2006) é a do sujeito pós-moderno. Calcada no pensamento contemporâneo de que se vive em novos contextos sociais, políticos e culturais dos quais emergem processos culturais e econômicos globalizados, política de neoliberalismo e novos movimentos sociais e culturais, essa concepção tem difundido a formação de um sujeito que "assume identidades diferentes em diferentes momentos, identidades que não são unificadas ao redor de um eu coerente" (HALL, 2006, p. 13). À medida que a sociedade se transforma, as culturas se modificam, surgindo uma multiplicidade de identidades com as quais os sujeitos se confrontam e, possivelmente, se identificam.

Essa concepção representa a desconstrução das concepções de sujeito anteriormente apresentadas, pois nessa perspectiva a identidade não é estável, unificada ou interativa, mas composta de várias identidades, constituída por um processo provisório, problemático e complexo, marcado por diferentes elementos de discursos políticos, culturais, históricos e subjetivos. Portanto, são consideradas identidades descentradas. "A identidade é, portanto, uma noção contraditória e, também, multidimensional que leva em conta as diferentes dimensões (tanto afetiva, como cognitiva e social) que constituem a personalidade, o indivíduo" (POURTOIS 1999, p. 59).

Dubar (2006), sociólogo francês, no estudo sobre crise identitária, utiliza o termo "formas identitárias" para conceituar as mutações e transformações que os indivíduos passam nos determinados tempos históricos. Para justificar o uso do termo, o autor situa as diversas acepções sobre identidade a partir de duas grandes correntes filosóficas, a saber: a essencialista e a nominalista ou existencialista. A primeira centra-se na ideia da existência de substâncias imutáveis e originais dos seres, ou seja, há uma permanência no tempo das caracte- rísticas comuns aos seres (mesmidade), que impossibilita as mudanças. Essa concepção foi acrescentada pela ideia da necessidade de categorizar os seres, reagrupálos a partir de suas essências comuns. A essência comum a todos os seres semelhantes, que os fazem diferentes de outras essências, é chamada de ipseidade ${ }^{3}$ o que caracteriza o ser como ser único, singular, que é diferente do outro.

A segunda corrente, a nominalista ou existencialista, concebe a identidade como resultado de uma identificação contingente. Diferente da essencialista, essa corrente defende que os modos de identificação são históricos e contextuais (DUBAR, 2006). Essas formas identitárias são construídas a partir de processos de atribuição, a que o autor denomina de identificações para o outro, o sujeito é o que o outro espera que ele seja, e de reivindicação, identidade para si, o que o sujeito é a partir de suas escolhas. No entanto, esses processos não acontecem de modo fragmentado, eles podem coincidir ou divergir. $\mathrm{O}$ sujeito pode tomar para si uma pertença herdada e atribuída pelos outros como a única a se identificar, ou pode se definir diferentemente das formas atribuídas pelos outros.

No intuito de analisar as diferentes maneiras em que foram pensadas diversas figuras identitárias, bem como para aprofundar a questão do significado subjetivo das formas de individualização nas sociedades contemporâneas, Dubar (2006, p. 21) aborda três grandes processos históricos que influenciaram as mudanças dos processos de identificação, tais como: o processo de civilização de Norbert Elias, processo de racionalização de Max Weber e o processo de libertação de Marx e Engels. $\mathrm{O}$ autor demonstra que as discussões desses processos, apresentadas por esses teóricos, "são úteis, mas insuficientes para permitir a conceptualização do processo histórico das formas identitárias".

Considerando que, após períodos de guerra, os totalitarismos políticos sujeitaram os indivíduos a desigualdades econômicas e à exclusão em massa do acesso à modernidade, Dubar (2006) defende que:

nem a identidade de Corte, característica dos Estados burocráticos 'modernos', nem a identidade do empresário 'racional' impondo num mercado uma lógica econômica capitalista, nem o militante revolucionário, fundido em sua Causa 'comunista' e o aparelho que pretende encarná-la, podem servir de polo de

\footnotetext{
${ }^{3}$ Relacionado à "identidade compreendida no sentido de um si mesmo(ipse)[...] instruído pelas obras da cultura que aplicou a si mesmo" (RICOEUR 1997. p. 425)
} 
identificação comum, universal legítimo e desejável.

DUBAR ressalta que as formas apresentadas estão relacionadas com o que cada um gere, combina e planeja na vida cotidiana, sendo que o uso de determinadas formas depende do contexto das relações, como também dos "recursos de identidade' ${ }^{4}$ das pessoas visadas.

O termo identidade é tomado por Ricoeur (1997) no sentido de uma categoria da prática. Para esse autor, falar sobre identidade de um indivíduo é responder às perguntas: quem faz tal ação? Quem é seu agente, seu autor? Em busca de resposta para essas questões, ele forja o conceito de identidade narrativa, como a construção, em ação, das experiências significantes que incluem mudanças, mutabilidade.

A representação de si pressupõe a descrição simbólica do percurso de vida, do tempo, do espaço e do lugar que um acontecimento singular pode ocupar na existência do sujeito. Nesse sentido, a identidade narrativa é o processo de biografização do sujeito que, segundo Delory-Momberger (2008, p. 27), emerge como uma "hermenêutica prática, um quadro de estruturação e significação da experiência por intermédio do qual o indivíduo se atribui uma figura no tempo, ou seja, uma história que ele reporta a um si mesmo"; é uma historialidade da consciência de si. Como sujeito histórico, o indivíduo escreve sua história não apenas a partir da singularidade de sua existência, como também a partir do ser social que ele também é, pois como sujeito, ele é membro de uma comunidade com modelos biográficos padronizados. Assim sendo, a individualização e socialização são partes integrantes da biografização. Segundo Delory-Momberger (idem), "assim entendida, a biografização não é somente um processo sócio historicamente inscrito, formal e estruturalmente determinado; é um processo essencial de socialização e de construção da realidade social" (p.28).

Embora os conceitos forjados pelos autores não façam referências aos processos identitários da docência, eles servem de base para entendermos a constituição da docência como profissão que possui um papel social que lhe imprime uma identidade profissional, de caráter multicompôsito, constituída por dimensões individuais ou biográfica e sociais, com saberes, poderes e subjetividades diversas.

4 (DUBAR 2006), em nota de rodapé p. 50, afirma que, numa perspectiva nominalista, os recursos identitários "só podem ser considerados como capacidades linguísticas, reservas de palavras, expressões, referência que permitem por em marcha estratégias, mais ou menos complexas, de identificação dos outros e de si próprio".
Em relação à dimensão da identidade biográfica, os estudos sobre a profissão de professor, entre eles o de (MOITA, 1995), têm pontuado como marco da preocupação com a pessoa do professor, a publicação do livro O professor é uma pessoa, de Ada Abrahan, em 1984. De acordo com (MOITA, 1995), essa publicação coloca o professor no centro do debate educativo e das problemáticas de pesquisas e, consequentemente, observa-se o advento de literaturas sobre a vida, as carreiras, os percursos profissionais e desenvolvimento pessoal dos professores. Essas pesquisas têm contribuído para a compreensão de como o sujeito torna-se professor, dos modos de ensinar e ser docente, ou seja, da relação entre o eu profissional e pessoal. A constatação dos estudos é de que a construção da identidade não é um percurso linear, estático, ao contrário, é percurso dinâmico de lutas, conflitos e conquistas e que o professor é um profissional que constrói e reinventa sua identidade, saberes e conhecimento.

Olhando por esse prisma, Moita (1995, p. 116) assinala que a identidade

é uma construção que tem uma dimensão espácio-temporal, atravessa a vida profissional desde a fase da opção pela profissão até à reforma, passando pelo tempo concreto da formação inicial e pelos diferentes espaços institucionais onde a profissão se desenrola. É construída sobre saberes científicos e pedagógicos como sobre referências de ordem ética e deontológica.

A partir do exposto, percebe-se a existência de um processo dual em que acontecem duas transações, conforme identificado por Dubar (2006): uma transação interna ao indivíduo (subjetiva), e outra, externa (objetiva), a qual acontece entre o indivíduo e as instituições com as quais ele se relaciona. Nesse sentido, não há uma separação entre a pessoa e sua profissão, que constitui sua identidade social ou uma prevalência de um ou outro, mas uma interação entre os dois processos identitários: subjetivo e objetivo. Para a teoria da socialização de Claude Dubar, a identidade nada mais é do que "o resultado a um só tempo estável e provisório, individual e coletivo, subjetivo e objetivo, que, conjuntamente, constrói os indivíduos e definem as instituições" (DUBAR, 2006 p. 136). Tomando como base a identidade profissional, pode-se indagar: essa seria o amálgama desses dois pólos? Como acontece essa relação? Como se dá a articulação entre o mundo subjetivo e o mundo objetivo na construção da identidade social?

Para a compreensão desse processo, Dubar (2006) 
sugere o estudo de duas categorias: a atribuição e o pertencimento, conforme mostra o Quadro 1 .

Quadro 1: Categorias de análise da identidade

\begin{tabular}{|c|c|}
\hline $\begin{array}{l}\text { Processo } \\
\text { relacional }\end{array}$ & $\begin{array}{l}\text { Processo } \\
\text { biográfico }\end{array}$ \\
\hline * & $*$ \\
\hline Identidade para o outro & $\begin{array}{l}\text { Identidade } \\
\text { para si }\end{array}$ \\
\hline $\begin{array}{l}\text { Atos de atribuição } \\
\text { "Que tipo de } \\
\text { homem ou de } \\
\text { mulher você é" } \\
=\text { dizem que você,é }\end{array}$ & $\begin{array}{l}\text { Atos de pertencimento, } \\
\text { "Que tipo de homem } \\
\text { ou de mulher você } \\
\text { quer ser"= você diz } \\
\text { que você é }\end{array}$ \\
\hline$*$ & $*$ \\
\hline $\begin{array}{l}\text { Identidade } \\
\text { numérica } \\
\text { (nome atribuído) - } \\
\text { genérica } \\
\text { (gênero atribuído) }\end{array}$ & $\begin{array}{l}\text { Identidade } \\
\text { predicativa } \\
\text { de si (pertencimento } \\
\text { reivindicado) }\end{array}$ \\
\hline$*$ & $*$ \\
\hline $\begin{array}{l}\text { Identidade social } \\
\text { "virtual" }\end{array}$ & $\begin{array}{l}\text { Identidade social } \\
\text { "real" }\end{array}$ \\
\hline$*$ & $*$ \\
\hline $\begin{array}{l}\text { Transação objetiva entre } \\
\text { - identidades atribuídas } \\
\text { propostas - identidade } \\
\text { assumidas incorporadas }\end{array}$ & $\begin{array}{l}\text { Transação subjetiva } \\
\text { entre } \\
\text { - identidades herdadas } \\
\text { - identidades } \\
\text { visadas }\end{array}$ \\
\hline$*$ & $*$ \\
\hline $\begin{array}{l}\text { Alternativas } \\
\text { entre } \\
\text {-cooperação } \\
\text { - reconhecimento } \\
\text { - conflitos } \\
\text {-não reconhecimento }\end{array}$ & $\begin{array}{l}\text { Alternativas } \\
\text { entre } \\
\text { - continuidades } \\
\text { - reprodução } \\
\text { - rupturas } \\
\text { - produção }\end{array}$ \\
\hline$*$ & $*$ \\
\hline $\begin{array}{l}\text { "Experiência } \\
\text { relacional } \\
\text { e social do PODER" }\end{array}$ & $\begin{array}{l}\text { "Experiência } \\
\text { de estratificações, } \\
\text { discriminações e } \\
\text { desigualdades sociais" }\end{array}$ \\
\hline * & $*$ \\
\hline $\begin{array}{l}\text { Identificação } \\
\text { com } \\
\text { instituições consideradas } \\
\text { estruturantes ou legítimas }\end{array}$ & $\begin{array}{l}\text { Identificação } \\
\text { com categorias } \\
\text { consideradas atraentes } \\
\text { ou protetoras }\end{array}$ \\
\hline *identidade social & $\begin{array}{l}\text { marcada } \\
\text { pela dualidade* }\end{array}$ \\
\hline
\end{tabular}

Fonte: (DUBAR, 2006, p. 142)
A primeira categoria, a atribuição, resulta das relações de força travadas no interior dos sistemas de ação entre os diversos autores. Nessa relação, acontecem os atos de atribuição da identidade pelas instituições e seus dirigentes, em que se define que tipo de homem/profissional se é. Dessa forma, é um processo de identificação para o outro, ou processo relacional. Em relação à profissão docente, percebe-se que, ao longo da história de sua profissionalização, foram-lhe atribuídas várias identidades pelos "sistemas peritos" (GIDDENS, 2002), tais como: professores críticos, construtivistas, tradicionais, competentes, reflexivos etc. A cada momento histórico, a cada mudança de pensamento, seja político, econômico, acadêmico, social, é elencado um perfil docente que define o tipo de profissional que ele é ou deve ser.

A segunda categoria, o pertencimento, refere-se ao processo de assimilação da identidade pelos indivíduos, que DUBAR denomina de legitimidade subjetiva e chama atenção para o fato de que só "pode ser analisada no interior das trajetórias sociais pelas quais e nas quais os indivíduos constroem identidades para si" (DUBAR, 2006, p. 139) e definem que tipo de ho$\mathrm{mem} /$ profissional querem ser ou dizem que são. O processo de pertencimento se dá pela legitimação de valores, condutas e ação para si e para o grupo, a partir do qual o indivíduo define sua identidade individual. No entanto, esse grupo de pertença nem sempre é o mesmo que lhe foi atribuído por outrem (instituição), gerando uma desarticulação e, consequentemente, uma crise entre os dois pólos identitários. Para a redução da distância entre as duas identidades, criam-se, segundo Dubar (2006), "estratégias identitárias" que podem ser colocadas em práticas por meio de

transações 'externas' entre o indivíduo e os outros significativos, visando a tentar acomodar a identidade para si à identidade para o outro (transação denominada "objetiva”), ou a de transações 'internas' ao indivíduo, entre a necessidade de salvaguardar uma parte de suas identificações anteriores (identidades herdadas) e o desejo de construir para si novas identidades no futuro (identidades visadas), com vistas a tentar assimilar a identidade-para-o-outro à identidade-para-si. (DUBAR, 2006, p. 140).

Consideramos que, ao fazer as transações para a construção de sua identidade, o sujeito realiza reflexão sobre si e seu papel social, sobre sua ação e consciência de mundo, valores, sentimentos. Esse processo implica 
uma trajetória através de diferentes situações de vida; uma imersão em si e na cultura. Implica viver a experiência de se constituir um sujeito individual e coletivo. Essa concepção de identidade profissional ancora-se na Teoria Interacionista das profissões, a qual concebe a socialização profissional como um processo descontínuo centrado na relação dos sujeitos com seus pares e pelo reconhecimento social da profissão. Tal concepção contrapõe-se à Teoria Funcionalista que define a profissão como atividade ancorada apenas no saber científico e com padrões definidos que reúnem os mesmos valores éticos profissionais formados por um processo linear, altruísta (DUBAR, 2006; RODRIGUES, 1997).

Com a concepção interacionista, alguns aspectos são introduzidos no âmbito dos estudos das profissões no que se refere à individualidade do sujeito profissional, à identidade de pertencimento à comunidade, à experiência prática, aos processos biográficos, dentre outros. Esses aspectos tornaram-se essenciais para o entendimento do processo de construção da identidade docente, pois, para compreender o profissional professor é necessário investigar não apenas a dimensão social em que a profissão é forjada, mas os processos individuais e relacionais que formam o ser professor.

Para compreendermos a implicação desses aspectos no processo identitário docente, no próximo tópico, lançaremos um olhar multirreferencial sobre a segunda categoria constitutiva de nosso estudo: a experiência e seu papel no processo identitário do professor.

\section{A EXPERIÊNCIA COMO ELEMENTO FOR- MATIVO DO SUJEITO SINGULAR-PLURAL}

Experiência é uma categoria presente nas grandes discussões teóricas acerca do conhecimento. De acordo com teóricos que discutem o conceito de experiência, tais como Dubet (1994), Larrosa (2004), Mahfoud e Massimi (2008), desde os filósofos clássicos, como Platão, Aristóteles e Santo Agostinho, o tema é norteado pela dualidade entre corpo e espírito, entre razão e emoção, entre indivíduo e sociedade, singular e universal, caracterizando-se como uma temática complexa devido à diversidade de abordagens e às contradições presentes nas discussões. Configura-se como categoria de estudo nos campos da filosofia, da epistemologia, da psicologia, da sociologia, da história e da educação.

Entre esses campos de conhecimento existem duas concepções de experiência: uma ligada à singularidade humana e outra que a converteu em experimento científico. Na primeira concepção, a experiência é uma maneira de sentir, e, portanto, está relacionada ao lado emocional. O sujeito deposita toda a descoberta numa subjetividade pessoal, como no caso da experiência estética, amorosa, religiosa. Segundo Dubet (1994), essa noção é ambivalente, pois congrega duas perspectivas: por um lado, a experiência é propriamente individual, irracional, manifestação de uma história particular. Por outro lado, a experiência é a consciência individual da sociedade em que a emoção individual se une à emoção comum, coletiva, cultural. Na segunda concepção, a experiência é uma atividade cognitiva, é um modo de construir a realidade, e, sobretudo, de testar, de experimentar. Trata-se da concepção racional da experiência, visto que os fenômenos são construídos a partir de categorias do conhecimento e da razão científica.

Essa última perspectiva, forjada pelo pensamento científico moderno, é caracterizada pela separação em definitivo entre o espírito e a razão. Com o advento da revolução científica, é considerado verdadeiro o conhecimento produzido por meio da verificação metodológica, racional e científica, desconsiderando qualquer influência subjetiva ou do mundo sensível. Até a atualidade, essa concepção predomina como forma verdadeira de apreensão do mundo. No entanto, as indagações sobre o seu estatuto na aprendizagem do homem no mundo ainda permanecem e presencia-se uma crescente discussão acerca da legitimidade da experiência e seu papel fundamental para o processo de formação e aprendizagem humana. Destarte, indagamos: pode a experiência ser considerada exterior ao homem? Podese falar em diferentes tipos de experiências? Pode-se aprender pela experiência? A experiência é formadora?

Para Larrosa (2004), a experiência tem sido menosprezada tanto pela racionalidade clássica quanto pela racionalidade moderna. Na filosofia clássica, mesmo sendo considerada como ponto de partida para o verdadeiro conhecimento, a experiência era entendida como um conhecimento inferior. O autor afirma que, para Platão, a experiência é o que está no mundo sensível, no mundo das aparências, portanto, o saber da experiência está mais suscetível à opinião do que a verdadeira ciência, por que a ciência é sempre o que é, do inteligível, do imutável. Na mesma perspectiva, para Aristóteles, a experiência é necessária, mas não suficiente. Ela é inferior à arte e à ciência, pois pertence ao singular e a ciência é universal. Na ciência moderna, a experiência é objetivada, controlada, convertida em experimento.

Pero con eso elimina lo que la experiência tiene de experiencia y que es, precisamente, la impossibilidad de objetivacion y la impossibilidad de universalización. La experiência es siempre de alguien, subjetiva, es siempre de aquí y ahora, contextual, finita, provisio- 
A DIMENSÃO EXPERIENCIAL COMO ELEMENTO CONSTITUTIVO DA IDENTIDADE DOCENTE

nal, sensible, mortal, de carne y hueso, como

la vida misma (LARROSA, 2004, p. 22).

Para o autor, experiência é o que nos passa, nos toca, nos acontece. Para ele, não há separação entre a experiência e a vida, ela é a própria existencialidade do ser. Como a própria existencialidade, ela é fluida, indeterminada, singular. Portanto, deve-se pensar a experiência não a partir de uma lógica de ação ou da reflexão do sujeito sobre si mesmo como agente, mas pela lógica da paixão. Larrosa (2002) concebe o sujeito como passional no sentido de estar aberto, exposto à experiência. Isso não quer dizer que o sujeito seja inativo, pois, para ele, da paixão também se desprende uma epistemologia e uma ética, talvez inclua uma política e uma pedagogia. No sentido de que a paixão refere-se a certa heteronomia, ou a certa responsabilidade em relação com o outro, por quem ou pelo quê se apaixona. Além disso, o sujeito passional, ao experienciar, se expõe, se posiciona. À medida em que vai respondendo e dando sentido ao que vai lhe acontecendo no decorrer da vida, ele mostra sua força por meio de seu saber, em forma de práxis.

Encontramos, nos estudos históricos e sociológicos de Thompson (1981) e Dubet (1994), a contribuição para o entendimento da experiência no âmbito da relação do sujeito com a cultura e com a sociedade. Ao expor a crítica sobre as ideias deterministas de Althusser, o historiador Thompson (1981) propõe que, se os acontecimentos pelos quais os sujeitos passam são singularizados, mas frequentemente confrontados com a consciência social existente, podem gerar novos problemas, provocar mudança no ser social e dar origem à experiência. Para o historiador, "a experiência compreende a resposta mental e emocional, seja de um indivíduo ou de um grupo social, a muitos acontecimentos interrelacionados ou a muitas repetições do mesmo tipo de acontecimento" (p.15). A experiência não é algo inusitado e instantâneo. Ela emerge espontaneamente no ser social, no entanto, não emerge sem pensamento, pois é fruto da reflexão dos sujeitos sobre o que acontece a ele e a seu mundo. Thompson alerta para o fato de que as pessoas experienciam o seu mundo não apenas como pensamento e ação, mas também pelos sentimentos.

Elas também experimentam sua experiência como sentimento e lidam com esses sentimentos na cultura, como normas, obrigações familiares e de parentescos e reciprocidades, como valores ou (através de formas mais elaboradas) na arte ou nas convicções religiosas. Essa metade da cultura (e é uma metade com- pleta) pode ser descrita como consciência afetiva e moral (THOMPSON, 1981, p. 189).

Esse é um conceito amplo, pois não se resume ao sujeito em sua singularidade, mas também as suas relações sociais, compondo a consciência social, afetiva, moral e cultural. Nesse aspecto, Dubet (1994) sugere a noção de experiência social como uma noção que representa comportamentos individuais e coletivos caracterizados pela heterogeneidade de seus princípios constitutivos e pela atividade dos indivíduos que constroem sentido para suas práticas no seio dessa multiplicidade. Para Thompson e Dubet, a noção de experiência está relacionada à ação do indivíduo, à consciência que ele tem do mundo e de si mesmo. Portanto, a experiência social não é um fluxo de sentimentos e emoção de único sujeito, pois é socialmente construída e envolve atividades dos indivíduos e sua capacidade crítica.

Nesse movimento entre os indivíduos e a atividade social, ou seja, da experiência social é que segundo $\mathrm{Re}-$ ale (1977), emerge a cultura, que dialeticamente põe a exigência de novas experiências. Nesse ponto, cabe a discussão sobre a qualidade das experiências, visto que nem de toda experiência poderá emergir a cultura e nem toda cultura exige novas experiências, pois nem toda cultura está aberta a modificações, como no caso de uma sociedade totalitária. Portanto, o movimento dialético de emergência e exigência de novas vivências se dá num leque de objetivações sempre abertas a novos testes, pois

Toda experiência por mais que pareça circunscrita à racionalidade pura ou a estritos relacionamentos factuais, alberga sempre um sentido de valor, sem o que não haveria seleção e a conseguinte apuração de resultados em virtude de sua adequação ou exigibilidade (requeredness) em função dos fatos. (REALE, 1977, p. 22).

Se tomarmos como parâmetro as sociedades denominadas pós-industriais ou sistemas complexos, poderemos dizer que o caráter axiológico da experiência está na base dos conflitos culturais, pois, como afirma $\mathrm{Me}$ lucci (2001, p. 71), a intervenção da sociedade dá-se sobre o sistema nas suas múltiplas lógicas reguladoras, "mas também sobre os indivíduos, sobre sua capacidade simbólica individual, sobre as possibilidades de cada um definir o sentido de sua própria ação". Antagonicamente, nesse processo de intervenção e construção de sentido ou de valoração de suas ações ou experiências repousa a possibilidade de superação do controle ou regulação dos sistemas sobre os indivíduos, ou seja, em 
torno da reapropriação do sentido da ação se constituem novos conflitos. Nesse sentido, a experiência é consciência de ação, que, por sua vez, compõe a identidade social, definida por Melucci como

a capacidade reflexiva de produzir consciência da ação (isto é, representação simbólica da mesma) além de seus conteúdos específicos. A identidade transforma-se em reflexividade formal, pura capacidade simbólica, reconhecimento da produção de sentido no agir, no interior dos limites colocados em um dado momento, pelo ambiente e pela estrutura biológica. (MELUCCI, 2001, p. 89).

Percebe-se que a experiência, como parte constitutiva da identidade, também abrange os dois campos dinâmicos dos indivíduos: uma interioridade e uma exterioridade e nessa relação entre si e o outro são forjadas as identidades. Na interação desses campos, por ter caráter axiológico, a experiência se constitui como um elemento formativo para o sujeito.

Para refletir sobre a experiência como elemento formativo, faremos um recorte metodológico no sentido de compreendê-la no âmbito do processo educativo, a partir do conceito de experiência formadora utilizado por Josso et al. (2004). A autora aborda o conceito de experiência como vivência acompanhada de uma formulação teórica e/ou de uma simbolização. A autora, inspirando-se inicialmente no pensamento de Dewey, defende que as vivências transformam-se em experiências a partir de um trabalho reflexivo sobre situações vivenciadas e sobre o que foi observado, percebido e sentido durante as situações.

Nessa perspectiva, a experiência implica o sujeito em sua globalidade, pois comporta as dimensões sensíveis, afetivas e conscienciais que envolvem emoções, sentimentos, valores e imagens sociais, construídas ao longo de uma vida e que foram sucessivamente trabalhadas para se tornarem experiências. Como elemento compósito de nosso devir identitário, a experiência constitui um referencial que nos auxilia para avaliação de situações, ações e acontecimentos no decorrer de nossa vida.

Para compreendermos a construção da experiência no processo formativo das pessoas, Josso et al. (2004) sugere uma análise, tomando-se como referência três modalidades, caracterizadas como experiências feitas $a$ posteriori e a priori, tais como: "ter experiência”, que significa viver situações durante a vida que não foram provocadas pela pessoa; "fazer experiência", que são as vivências de situações criadas propositalmente; "pensar sobre as experiências" independentes que elas sejam inusitadas ou criadas por si mesmo. Esse processo de análise contribui para a distinção entre uma aprendizagem fortuita e uma refletida e para a compreensão de como o sujeito dá significação existencial ao conjunto de experiências vivenciadas. A autora chama a atenção para a distinção entre a "experiência existencial" que contempla a pessoa em sua totalidade, corresponde à identidade profunda do ser, e a "aprendizagem pela experiência" que está relacionada a pequenas transformações, contribui para mudar alguns aspectos da identidade, mas "não há verdadeiramente uma metamorfose do ser" (p. 55).

Nesse corpo de referências, buscamos a contribuição de Dewey (1971), como protagonista, no âmbito da filosofia da educação, na reivindicação por uma teoria da experiência para pensar e praticar a educação. Criticando a educação tradicional devido à separação entre o conhecimento comum e o científico, pela concepção de educação como uma preparação para a vida adulta e pela concepção de aprendizagem unilateral, que acontece de fora para dentro, Dewey propõe uma educação que cultive também a individualidade, a atividade livre, a necessidade do aluno, o tempo presente, o mundo em mudança e a experiência. Para ele, a experiência é base para o processo formativo, para a construção de aprendizagens. Como os teóricos anteriormente citados, Dewey faz referência ao sentido de valor das vivências, pois nem toda experiência é experiência. Tudo depende da qualidade, do sentido de valor da experiência, que repousa sobre o efeito dela sobre o indivíduo.

Com base na ideia de Dewey (1971, p. 14) que "a crença de que tôda educação genuína se consuma através da experiência não quer dizer que tôdas experiências são genuínas e igualmente educativas", podemos dizer que nem toda vivência se transforma em experiência ou nem toda experiência é formadora. Concordando com o autor, acreditamos que, para uma experiência ser formadora, é necessário uma atitude reflexiva mediante a qualidade da situação vivenciada, ou seja, é preciso analisar o nível de influência para a criação de outras experiências. Estando em constante movimento, o seu valor não pode ser avaliado se não na base de para quê e para onde se encaminha. Esse é um aspecto caracterizado por Dewey como princípio da continuidade, ou "continuum experiencial", ou seja, toda experiência possui algo das experiências passadas e modifica as outras posteriores. Com base nesse princípio, no processo educativo, deve-se atribuir o sentido de transformação e criação. Deve-se refletir sobre as experiências que irão 
influenciar criadoramente nas experiências futuras, sobre o seu valor educativo.

Dewey também caracteriza a experiência como um movimento interno e externo ao indivíduo, visto que a mesma não se processa apenas no interior individuo. Ela também é influenciada por fatores sociais ou diferentes ambiências que alimentam a emergência de experiências.

[...] vivemos do nascimento até a morte em um mundo de pessoas e cousas que, em larga medida, é o que é devido ao que se fêz e ao que nos foi transmitido de atividades humanas anteriores [...] Dispensável repetir que a experiência não sucede no vácuo. Há fontes fora do indivíduo que a faz surgir. E essas nascentes a alimentam constantemente (DEWEY, 1971, p. 31).

Essa citação explicita o outro princípio formulado pelo autor, que é o da interação, a experiência ocorre na relação da pessoa com o meio, podendo este ser pessoas, objetos, ambientes. Nesse caso, a subjetividade e a objetividade têm influência direta nas vivências formativas. Embora Dewey afirme que toda experiência humana é, em última análise, social, pois envolve contato e comunicação, e discuta a questão do controle social, ele se distancia do conceito de experiência social cunhado por Thompson e Dubet, na medida em que esses autores fazem uma leitura da experiência pela vertente histórico- social, concebendo-a como elemento que exerce pressão sobre a consciência coletiva e, portanto, traz implícita a questão da transformação da realidade.

Dewey concebe o social não no sentido de sociedade ou sistema, mas de ambiência. A experiência não está ligada necessariamente à consciência social, mas a um organismo que interage com o meio em que vive e que precisa refletir sobre sua vivência para que tenha um processo formativo significante. Nesse sentido, a experiência aproxima-se mais do sentido de adaptação ao social do que necessariamente de sua transformação. Ao reportar-se ao papel do educador no processo formativo, o autor argumenta: "acima de tudo, deve saber como utilizar as condições físicas e sociais do ambiente para delas extrair tudo o que possa contribuir para um corpo de experiências saudáveis e válidas" (1971, p 32).

A partir das contribuições teóricas acima, conceituo a experiência como um movimento para si, mas que se realiza na interação com o outro, com o conhecimento, com a diversidade de práticas e vivências sociais cotidianas, intermediado por um movimento de reflexão sobre a experiência. A partir desse conceito atribuído, refletiremos sobre o pensar e o fazer da prática docente.

\section{EXPERIÊNCIA REFLETIDA: DIÁLOGO EN- TRE O PENSAR E O FAZER NA PRÁTICA DOCENTE}

O pensamento reflexivo do professor constitui um aspecto relevante nos estudos no campo da epistemologia da prática docente. De acordo com Schön (2000), pioneiro das investigações sobre a prática reflexiva, o pensamento prático do professor é constituído por três processos, a saber: o conhecimento na ação, reflexão na ação e a reflexão sobre a ação.

O conhecimento-na-ação é constituído pelo conhecimento implícito na ação. É um saber mobilizado espontaneamente, sem uma reflexão anterior, no enfrentamento das situações cotidianas, proporcionando os resultados esperados pelo professor. "Nós o revelamos pela nossa execução capacitada e espontânea da performance, e é uma característica nossa sermos incapazes de torná-la verbalmente explícita" (SCHÖN, 2000. p. 31). Em outras palavras, nesse processo, mesmo que tentemos descrever a ação, a descrição será sempre aproximações. O conhecimento-na-ação refere-se às habilidades, ações, decisões, atitudes que o professor toma espontaneamente, rotineiramente sem deliberações conscientes. Refere-se ao conhecimento tácito do professor.

A reflexão-na-ação é o movimento cognitivo do professor de questionar-se diante das situações conflitantes em suas atividades rotineiras. Nesse processo reflexivo, o professor reflete durante os acontecimentos de sala de aula, nas ações dos alunos, problematizando as situações e colocando novas questões. É uma reflexão consciente; tem uma função crítica; ajuda a estruturar as estratégias de ação sem uma sistematização teórica (SCHÖN 2000).

A reflexão sobre a reflexão-na-ação está relacionado ao processo realizado após a situação vivenciada. Nesse estágio, o professor faz uma retrospectiva de suas ações em situações problemáticas, mobiliza seus conhecimentos para analisar, interpretar as ações anteriores e, assim, reconstruir a sua prática. $\mathrm{O}$ ato de refletir sobre a reflexão-na-ação possibilita a verbalização da ação, proporcionando o diálogo entre o pensamento e a ação, o qual aciona mais competência e habilidade para compreender o problema (SCHÖN, 2000).

A partir da década de 1990, a epistemologia da prática proposta por Schön influenciou os estudos sobre a docência. Tais estudos compreendem o professor como um profissional que, além de ter domínio do conheci- 
mento de sua disciplina, do programa que ela integra e de conhecimentos científico e pedagógico, desenvolve um saber prático alicerçado em sua experiência em sala de aula (TARDIF; LESSARD; LAHAYE, 1991). Portanto, considera-se que os professores refletem sobre suas experiências de sala de aula e constroem uma visão de contexto, que é usada como parâmetro para interpretação das situações cotidiana.

Os estudos conotam também que as singularidades das práticas pedagógicas revelam um saber-fazer docente que dar sentidos aos métodos e aos recursos na sala de aula. Por fim, pode-se dizer que, ao inventar, criar e pesquisar sobre os seus instrumentos de trabalhos, os professores constroem performances docentes que representam o modo como cada um ensina, as quais influenciam e constituem as práticas sociais produtoras de conhecimentos da docência. Assim sendo a experiência prática docente constitui a cultura docente. Em outras palavras, os saberes que emergem da prática formam um conjunto de representações pelas quais os professores compreendem e interpretam a sua profissão, constituindo, assim, a "cultura docente em ação". Como assinala Tardif, Lessard e Lahaye (1991), os saberes da prática representam

O conjunto dos saberes atualizados, adquiridos no quadro da profissão docente, e que não provém das instituições de formação ou dos currículos. Esses saberes não se encontram sistematizados no quadro de doutrinas ou de teorias...Eles formam um conjunto de representações a partir das quais o (a)s professore(a)s interpretam, compreendem e orientam sua profissão e sua prática cotidiana em todas as suas dimensões. Eles constituem, poder-se-ia dizer, a cultura docente em ação (TARDIF; LESSARD; LAHAYE, 1991. p. 228).

É importante assinalar que como a ação docente é uma atividade relacional realizada em rede de interação com outras pessoas, envolvendo saberes, sentimentos, emoções etc., o saber da experiência não é uma construção solitária. Segundo Tardif, Lessard e Lahaye (1991), os saberes da experiência têm três objetos-condições com os quais interagem: as relações e interações com os diversos atores da prática educativa, as normas e obrigação da profissão e a instituição. Através do enfrentamento das demandas postas por esses objetos-condições, o professor vivencia experiência, construindo, assim, os saberes da prática ou saberes da experiência. Por está condicionado a fato- res/objetos externos os quais influenciam na construção da performance docente, o valor da experiência dependerá do nível das relações estabelecidas entre o profissional professor com os objetos-condições.

\section{CONSIDERAÇÕES FINAIS}

O olhar multirreferencial lançado aos estudos que fundamentam o presente texto possibilitou a compreensão da importância do saber da experiência no processo identitário da docência. Os aportes teóricos com os quais dialogamos corroboram a ideia de que tanto a experiência quanto a identidade são categorias concebidas no entrelaçamento da dinâmica entre os aspectos individual e coletivo, singular e plural que compõem o sujeito professor.

Vimos que a identidade profissional do professor é uma das dimensões de sua identidade social. Como parte constitutiva do sujeito, ela é o resultado do processo dual entre a identidade biográfica e a identidade social, sendo constituída por atos de pertencimento ou de atribuição. Assim, a dinâmica identitária profissional acontece num processo de socialização do professor, pelo qual recebe influências, vivencia experiências, faz suas escolhas e constrói seu desenvolvimento profissional.

Nesse processo de socialização, a experiência ocupa uma dimensão relevante para a identificação ou pertencimento do sujeito à profissão docente, pois a docência não se constitui a priori, a docência é construída aos poucos, ao longo de um percurso, influenciada por diversos espaços de socialização e experiência; é através das experiências vivenciadas que o Eu pessoal interage com o Eu profissional, tecendo, assim, uma dinâmica identitária.

\section{REFERÊNCIAS}

DELORY-MOMBERGER, C. Biografia e educação: figuras do indivíduo-projeto. : EDUFRN, 2008.

DEWEY, J. Experiência e educação.(1938). Trad. Anísio Teixeira. São Paulo: Cia Editora Nacional, 1971.

DUBAR, C. A socialização: construção das identidades sociais e profissionais. : São Paulo: Martins Fontes, 2006.

DUBET, F. Sociologie de l'expérience (paris, éditions du seuil). 1994.

HALL, S. A identidade cultural na pós-modernidade. : TupyKurumin, 2006. 
JOSSO, M.-C.; NÓVOA, A.; CLÁUDIO, J.;

FERREIRA, J. Experiências de vida e formação. 2004. de ciências sociais. sociologia). Disponível em: $<$ https:

//books.google.com.br/books?id=AsPmZwEACAAJ>

LARROSA, J. Notas sobre a experiência e o saber de experiência. tradução joão wanderley geraldi. universidade estadual de campinas. departamento de linguística. Revista Brasileira de Educação, n. 19, 2002.

Algunas notas sobre la experiencia y sus lenguajes. Trajetórias e perspectivas da formação de educadores. São Paulo: Editora UNESP, p. 19-34, 2004.

LOPES, A. La construcción de identidades docentes como constructo de estructura y dinámica sistémicas: argumentación y virtualidades teóricas y prácticas. 2011.

MAHFOUD, M.; MASSIMI, M. A pessoa como sujeito da experiência: contribuições da fenomenologia. Memorandum, v. 14, p. 52-61, 2008.

MELUCCI, A. A invenção do presente: movimentos sociais nas sociedades complexas. Petrópolis, RJ:

Vozes, 2001. (trad.) Maria do Carmo Alves de Bomfim.

MOITA, M. d. C. Percursos de formação e de trans-formação. Vidas de professores, v. 2, p. 111-140, 1995.

POURTOIS, J.-P. Educação pós-moderna (A). : Edicoes Loyola, 1999.

REALE, M. Experiência e cultura para a fundação de uma teoria geral da experiência. 1977.

RICOEUR, P. Tempo e Narrativa. Tomo III. Tradução Roberto Leal Ferreira. : Campinas: Papirus, 1997.

RODRIGUES, M. d. L.-S. d. Profissões, celta. Portugal (Oeiras), 1997.

SCHÖN, D. Educando o profissional reflexivo: um novo design para o ensino e a aprendizagem. Artes Médicas Sul, 2000. Disponível em: <https: //books.google.com.br/books?id=utjxsgEACAAJ >

TARDIF, M.; LESSARD, C.; LAHAYE, L. Os professores face ao saber: esboço de uma problemática do saber docente. Teoria e educação, Porto Alegre, v. 4, p. 215-233, 1991.

THOMPSON, E. A miséria da teoria ou um planetário de erros: uma crítica ao pensamento de Althusser ; tradução de Waltensir Dutra. Zahar, 1981. (Biblioteca 